\title{
Anti-serum validation for use in immunohistochemistry for Trypanosoma cruzi detection
}

\author{
Paulo Hernane Rabelo Azevedo ${ }^{[1]}$, Marcelo Antônio Pascoal Xavier ${ }^{[1]}$, \\ Glenda Nicioli da Silva ${ }^{[2]}$, Priscilla Almeida da Costa ${ }^{[3]}$, \\ Cláudia Martins Carneiro ${ }^{[4]}$ and Geraldo Brasileiro Filho ${ }^{[1]}$
}

\begin{abstract}
[1]. Departamento de Anatomia Patológica, Universidade Federal de Minas Gerais, Belo Horizonte, MG, Brasil. [2]. Departamento de Análises Clínicas, Escola de Farmácia, Universidade Federal de Ouro Preto, Ouro Preto, MG, Brasil. [3]. Departamento de Bioquímica e Imunologia, Universidade Federal de Minas Gerais, Belo Horizonte, MG, Brasil. [4]. Núcleo de Pesquisa em Ciências Biológicas, Universidade Federal de Ouro Preto, Ouro Preto, MG, Brasil.
\end{abstract}

\begin{abstract}
Introduction: The detection of Trypanosoma cruzi in tissue samples is important in many situations, such as testing of the reactivation of the infection. The detection of $T$. cruzi nests in endomyocardial biopsies (EMB) may be useful to evaluate graft rejection. Given their scarcity, such nests are not routinely identified. To increase the diagnosis sensitivity, immunohistochemistry (IHC) may serve as a promising strategy. Here, we validate an antiserum for the detection of T. cruzi infection by IHC. Methods: We used 1) positive controls (PCs) - $13 \mathrm{EMB}, 12$ skin biopsies, and 1 heart with T. cruzi nests as sections stained with hematoxylin and eosin (HE); 2) negative controls - a) 10 explant hearts and $10 \mathrm{EMB}$ with no amastigote nests or clinical/laboratory signs of chagasic infection; and b) eight samples with leishmaniasis, toxoplasmosis, or histoplasmosis; and 3) Cases - 31 EMB of chagasic patients with no parasite nests in HE sections but detected positive for T. cruzi DNA by polymerase chain reaction. As a primary antibody, a hyperimmune serum from T. cruzi-infected rabbits was used. Results: IHC results were positive for 21 of 26 PCs ( $80.8 \%)$ and one case of cutaneous leishmaniasis. In 4 of 31 cases, IHC revealed nests (12.9\%), which were undetected by conventional histological examination. Conclusions: This study shows that IHC with the tested antiserum increases the sensitivity of the diagnosis and may be recommended for routine use in EMB analyses of cardiac transplant patients with Chagas disease.
\end{abstract}

Keywords: Chagas disease. Heart transplantation. Immunohistochemistry. Trypanosoma cruzi.

\section{INTRODUCTION}

Chagas disease, a chronic systemic parasitic infection caused by the protozoan Trypanosoma cruzi, was discovered by Carlos Justiniano Ribeiro Chagas in $1909^{1}$. According to the World Health Organization (WHO), it is one of the most neglected diseases in the world ${ }^{2}$. An estimated 6 to 7 million people are infected worldwide, especially in Latin America ${ }^{3}$. Despite the successful programs to control the transmission of the etiological agent through vector and transfusion routes in Brazil in the last decade 4 , a considerable Brazilian population (about 3 to 4 million individuals) is infected by the parasite or is at the risk to develop serious lesions of the disease. Furthermore, the uncontrolled migration of people infected with $T$. cruzi poses a challenge to control new cases in non-endemic countries ${ }^{5-7}$ and urban areas of endemic countries ${ }^{8}$.

Corresponding author: Dr. Paulo Hernane Rabelo Azevedo. e-mail: paulopato21@gmail.com

Received 26 February 2018

Accepted 4 July 2018
The majority of infected individuals $(60 \%$ to $70 \%)$ fail to develop clinically apparent disease (indeterminate form). The remaining $30 \%$ to $40 \%$ present an anatomical clinical form of chronic cardiac, digestive (megaesophagus and/or megacolon), or cardio-digestive disease usually 10 to 30 years after the initial infection.

Chronic Chagas heart disease is the most serious and frequent manifestation of the disease. It affects $20 \%-30 \%$ of infected individuals and is an important cause of morbidity and mortality, as many individuals are unable to perform their usual activities and die of progressive heart failure and related complications ${ }^{9}$.

About $10 \%$ of patients with heart failure secondary to Chagas disease progress to New York Heart Association (NYHA) functional class IV ${ }^{10}$. In the last two decades, cardiac transplantation has become one of the therapeutic modalities and serves as the only strategy that may modify the natural progression of the disease ${ }^{11}$.

In addition to the complications seen in solid organ transplants, Chagas disease is characterized with the reactivation of chagasic infection, owing to the immunosuppressive treatment 
that patients receive to avoid graft rejection ${ }^{12}$. Reactivation of Chagas disease in patients with depressed cellular immunity has been observed since the $1960 \mathrm{~s}^{13}$.

There are several ways to recognize the reactivation of T. cruzi infection in transplanted individuals. In some cases, the clinical suspicion is related to the appearance of skin lesions that are suggestive of reactivation. Common manifestations of reactivation of chagasic infection are panniculitis, myocarditis with signs of heart failure, fever, fatigue, anorexia, diarrhea, meningitis, encephalitis, and stroke ${ }^{14-17}$.

Circulating T. cruzi is considered as a parasitological criterion for the diagnosis of acute phase or reactivation of chagasic infection by the II Brazilian Consensus on Chagas Disease and may be detected by several methods ${ }^{18}$. The parasitic deoxyribonucleic acid (DNA) may be effectively detected by molecular biology techniques, especially polymerase chain reaction (PCR) from blood samples or endomyocardial biopsies $(\mathrm{EMB})^{19}$. PCR becomes positive a few days or weeks before the traditional parasitological tests and prior to clinical signs of reactivation ${ }^{20,21}$. Given its high sensitivity, PCR results from blood samples should be interpreted with caution in subjects with chronic Chagas disease, as the test may be positive in immunocompetent or immunocompromised individuals without clinical signs of reactivation ${ }^{20,22}$.

Endomyocardial biopsies, routinely performed after transplantation, aim to evaluate the immune rejection of grafts and determine its intensity. A pathologist is asked to identify and grade cellular rejection (absent, mild, moderate, or severe cell rejection). This graduation is based on histopathological aspects seen in EMB, such as the number of foci and pattern of inflammatory infiltrate, myocardiocytic lesion, edema, hemorrhage, and vasculitis ${ }^{23}$. Conventional histopathological evaluation can idenfity the immunological rejection as well as amastigote nests of T. cruzi to confirm the reactivation of the infection in the implanted organ ${ }^{24,25}$. As such nests are small and very scarce, these are rarely identified in routine exams. To increase the sensitivity of the morphological method, immunohistochemistry (IHC) may serve as a promising technique, as it allows more precise identification of sparse and very small nests.

The morphological evaluation of EMB after cardiac transplantation is a part of the protocol in these patients and has enormous practical importance because it guides immunosuppressive treatments in cases of cellular rejection and detects possible reactivation of the chagasic infection, which needs specific antiparasitic treatment. In these two scenarios with different clinical behaviors, the pathologist may contribute to the diagnosis of reactivation. However, it is difficult to make the differential diagnosis between moderate/severe acute cell rejection and reactivation of the chagasic infection, as the inflammatory infiltrate in both situations is morphologically indistinguishable.

Immunohistochemistry method has been used for the detection of $T$. cruzi antigens for more than 30 years $^{26}$. Since then, it has been shown to facilitate the identification of parasites, especially small nests, as compared to conventional pathological examination ${ }^{27}$.
Previous studies have shown that the anti-T. cruzi polyclonal antiserum can detect the parasite in both human and other animal tissues. The highest detection rates were observed during the acute phase of the disease and in cases of chronic phase with active inflammation ${ }^{28-30}$. The detection rate is higher in heart samples than in brain samples ${ }^{31}$. Greater detection of the parasite was found in cases with moderate to severe inflammatory process ${ }^{32}$.

Despite the potential advantages of IHC in the detection of the reactivation of chagasic infection, there are no available commercial antibodies. This situation is probably associated with the lack of interest of technology companies in providing such an antibody, as Chagas disease diagnosis seems important only in countries with high prevalence of this disease.

The aim of this study is to validate an antiserum (polyclonal antibody) produced at a scientific research institution for the immunohistochemical diagnosis of T. cruzi infection.

\section{METHODS}

\section{Selection, inclusion, and exclusion of samples}

The Hospital das Clinicas da Universidade Federal de Minas Gerais (HC-UFMG) Heart Transplant Service has been assisting patients with end-stage heart failure since 2006. Up to 2016,81 patients with chagasic cardiopathy were submitted to heart transplantation. In this study, all the anatomopathological reports performed at the HC-UFMG Pathological Anatomy Laboratory from these patients after transplantation were reviewed and comprised 81 surgical specimens of cardiac explantation, 823 EMB, 18 skin/subcutaneous biopsies, and 1 autopsy of a chagasic patient who died after transplantation in order to select positive controls. Samples of EMB with insufficient material to acquire new histological sections and/or to extract DNA for PCR were excluded from the study.

\section{Ethical considerations}

The project followed all research standards involving human beings established in the Resolution 196 of the National Health Council to safeguard the rights and well-being of the people studied. The project was approved by the Research Ethics Committee (COEP) of UFMG.

\section{Endomyocardial biopsies}

Biopsies were performed at pre-established times and according to standard procedures at the HC-UFMG, following the recommendations of the Second Brazilian Guideline on Cardiac Transplantation ${ }^{33}$. From each patient, four or five endomyocardial fragments were obtained; these fragments were fixed in $10 \%$ formalin, processed for inclusion in paraffin, and cut into sections (5 $\mu \mathrm{m}$ thickness). From each sample, at least 15 staggered cuts were obtained and these were stained with hematoxylin and eosin (HE). All technical processing of the samples was performed in the Pathology Laboratory of the HC-UFMG.

\section{Positive controls}

Twenty-six HE-stained samples containing T. cruzi amastigote nests were selected as positive controls. These included 13 EMB, 12 skin biopsies, and 1 heart (autopsy) containing sections of left ventricle and interventricular septum. 


\section{Negative controls}

Two groups of samples included as negative controls were as follows: 1) Samples without evidence of T. cruzi infection. Twenty anatomopathological specimens without amastigote nests of $T$. cruzi were selected; the patients had no clinical manifestations or laboratory tests indicative of chagasic infection. 2) Eight samples with a parasite morphologically similar to T. cruzi and potentially capable of showing crossreaction. As $T$. cruzi and other microorganisms have some morphological similarities, leishmaniasis, toxoplasmosis, and histoplasmosis samples were included. These parasites or fungi were histologically confirmed by IHC analysis using their respective antibodies. In total, negative controls were represented by 10 explanted hearts, $10 \mathrm{EMB}, 6$ leishmaniasis, 1 toxoplasma, and 1 histoplasma samples.

\section{Cases}

Aside from the four or five tissue fragments from EMB for histopathological examination, one additional fragment was collected from all chagasic heart transplant patients in ethanol to evaluate for the presence of $T$. cruzi DNA by PCR, according to the current research protocol on Chagas disease carried out at HC-UFMG. From these samples, we selected 31 patients that were negative for parasite nests in conventional examination (HE) but positive for T. cruzi DNA in PCR test.

\section{Histopathological study}

All slides routinely examined for the evaluation of graft rejection were reviewed by two authors (Azevedo PHR and Brasileiro Filho G) for the validation of the histopathological findings, especially for the confirmation or exclusion of T. cruzi nests.

\section{Immunohistochemical study Antiserum production}

For the anti-T. cruzi polyclonal antibody (antiserum) production, three New Zealand rabbits, approximately 60 days old, were kept in individual cages at the Animal Science Center of the Federal University of Ouro Preto [Universidade Federal de Ouro Preto (UFOP)] and provided with food and water ad libitum. The use, maintenance, and manipulation of the animals followed the standards recommended by the Brazilian College of Animal Experimentation (COBEA).

The animals were intraperitoneally inoculated with $10^{7}$ blood trypomastigote form of T. cruzi Y strain obtained from mice previously infected with this strain. Six months after inoculation, the animals were submitted to general anesthesia and whole blood was collected by cardiac puncture with subsequent euthanasia.

The blood was left at room temperature $\left(20-25^{\circ} \mathrm{C}\right)$ in $10-\mathrm{mL}$ glass tubes for $1 \mathrm{~h}$ to induce clot formation and then centrifuged at $1,372 \mathrm{~g}$ for $10 \mathrm{~min}$. The serum obtained was homogenized, aliquoted, identified, and stored at $-80^{\circ} \mathrm{C}$ until testing.

The antiserum was assessed in immunohistochemical assays on paraffin-embedded section from heart, spleen, and intestine of mice and dogs uninfected or infected by different strains of T. cruzi and proved to be effective in these animal samples.
The antiserum preparation was carried out at the Nucleus of Research in Biological Sciences of UFOP.

\section{Immunohistochemical reaction}

The histological sections were overnight oven dewaxed at $56^{\circ} \mathrm{C}$, rehydrated with xylol baths (thrice for $5 \mathrm{~min}$ ), $100 \%$ and $80 \%$ ethyl alcohol (thrice each, for $5 \mathrm{~min}$ ), and running water for $5 \mathrm{~min}$. Heat-induced antigen retrieval was performed with $0.01 \mathrm{M}$ sodium citrate solution $(\mathrm{pH}=6.0)$ at $90^{\circ} \mathrm{C}$ for $20 \mathrm{~min}$. The sections were blocked with an endogenous peroxidase in a methanol/hydrogen peroxide mixture $(100 \mathrm{~mL}$ of methanol and $3.5 \mathrm{~mL}$ of $30 \%$ hydrogen peroxide) for $30 \mathrm{~min}$ at room temperature, followed by two washes in $10 \%$ phosphate buffered saline (PBS) solution (5 min each). The sections were subsequently blocked with skimmed milk powder diluted in $10 \%$ PBS (6g of skimmed milk powder in $100 \mathrm{~mL}$ of PBS) for $30 \mathrm{~min}$ at room temperature to block nonspecific binding. The sections were incubated with the primary antibody (1:400,000 dilution) in PBS $/ 1 \%$ bovine albumin (1870, Inlab, Diadema, Brazil) in a humid chamber at room temperature for $1 \mathrm{~h}$, followed by two washes with $10 \%$ PBS solution (5 min each). Next, the sections were incubated in a humid chamber for $30 \mathrm{~min}$ at room temperature with anti-immunoglobulin $\mathrm{G}$ (anti-IgG) secondary antibody (Novolink, Newcastle, UK), followed by two washes in $10 \%$ PBS solution (5 min each). Streptavidin-peroxidase complex (Kit Dako, LSAB, K0675, Carpintery, USA) was subsequently applied and the preparation was incubated for 30 min in a humid chamber at $37^{\circ} \mathrm{C}$. The peroxidase reaction was developed by incubation of the samples in DAB solution $(50 \mathrm{mg}$ of 3,3'-diaminobenzidine tetrahydrochloride in $200 \mathrm{~mL}$ of PBS and $400 \mu \mathrm{L}$ of $30 \%$ hydrogen peroxide) for $5 \mathrm{~min}$. To stop the reaction, the sections were washed in PBS for 5 min and counter stained with Harris hematoxylin for 3s. The samples were washed in running water for $5 \mathrm{~min}$, dehydrated, diaphanized in xylol, and mounted in Entellan (Merck, Darmstadt, Germany).

All sections were carefully examined under a microscope, initially under a panoramic view and then under 100 and 400× magnifications, to detect for signals indicative of target antigens of the antibody tested. Each positive sign of T. cruzi was topographed and subsequently compared to the sections stained with HE.

\section{Polymerase chain reaction}

As an alternative to detect chagasic infection in the samples studied, two PCR methods were used to test the fragments of heart biopsies for T. cruzi DNA as follows: 1) kinetoplast deoxyribonucleic acid polymerase chain reaction (kDNA PCR), specific amplification of a 330-bp fragment corresponding to the variable region of the mini-circle of the kDNA performed using primers $\mathrm{S} 35$ and $\mathrm{S} 36$, as described elsewhere ${ }^{21,34}$; 2) real-time PCR of the 24SarDNA gene, according to the method of Costa et $\mathrm{a}^{35}$. These proposed protocols based on the PCR directed to mitochondrial (kDNA) and nuclear (rDNA 24S $\alpha$ ) markers have been useful for the diagnosis of Chagas disease, owing to good diagnostic sensitivity and specificity ${ }^{35}$. For control groups (positive and negative), only kDNA PCR was performed; DNA samples were obtained from histological sections of paraffinembedded tissues. In the group cases, both PCR methods were 
used and DNA was extracted from fresh EMB collected in ethanol. Samples that were positive for at least one of the two PCR methods were considered as positive.

\section{RESULTS}

The results of the conventional histological (HE), DNA amplification (PCR), and IHC tests of all the cases examined in this study are summarized in Figure 1.

Immunohistochemical analysis of the 26 samples used as positive controls (13 EMB, 12 skin biopsies, and 1 necropsy of chagasic patient that died after transplantation) revealed amastigote nests in eight EMB (Figure 2), 12 skin biopsies, and the autopsy heart (21 cases, $80.8 \%$ ) (Figure 1). In five EMB (19.2\% of total positive cases), the amastigote nests identified with HE staining were not seen in the IHC reactions (Figure 1). Eleven of the 26 positive controls (42.3\%) were positive for the parasite DNA in PCR.

The IHC reaction with the anti-T. cruzi serum was negative in 27 of 28 negative control cases (96.4\%). For one sample of cutaneous leishmaniasis $(3.8 \%)$, the positive reaction with anti-T. cruzi antibody showed parasites dispersed in the interstitium (Figure 3). Both toxoplasma and histoplasma

\begin{tabular}{|c|c|c|c|c|}
\hline \multicolumn{5}{|c|}{ Positive controls } \\
\hline $\begin{array}{c}\mathrm{N}^{\circ} \\
\text { case }\end{array}$ & HE & PCR & IHC & Sample \\
\hline 1 & + & - & + & \multirow{12}{*}{$\begin{array}{l}\frac{\mathscr{0}}{\omega} \\
\stackrel{0}{0} \\
. \frac{0}{0} \\
. \frac{.}{\omega}\end{array}$} \\
\hline 2 & + & + & + & \\
\hline 3 & + & - & + & \\
\hline 4 & + & - & + & \\
\hline 5 & + & + & + & \\
\hline 6 & + & + & + & \\
\hline 7 & + & - & + & \\
\hline 8 & + & - & + & \\
\hline 9 & + & - & + & \\
\hline 10 & + & + & + & \\
\hline 11 & + & + & + & \\
\hline 12 & + & + & + & \\
\hline 13 & + & - & + & \multirow{13}{*}{ 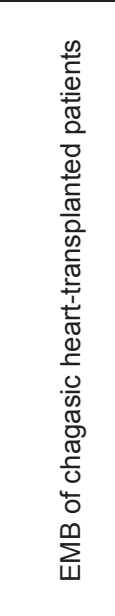 } \\
\hline 14 & + & - & - & \\
\hline 15 & + & + & + & \\
\hline 16 & + & + & - & \\
\hline 17 & + & - & - & \\
\hline 18 & + & - & - & \\
\hline 19 & + & - & + & \\
\hline 20 & + & - & + & \\
\hline 21 & + & - & + & \\
\hline 22 & + & - & + & \\
\hline 23 & + & + & + & \\
\hline 24 & + & - & - & \\
\hline 25 & + & + & + & \\
\hline 26 & + & + & + & Autopsy \\
\hline
\end{tabular}

\begin{tabular}{|c|c|c|c|c|}
\hline \multicolumn{5}{|c|}{ Negative controls } \\
\hline $\begin{array}{l}\mathrm{N}^{\circ} \\
\text { case }\end{array}$ & HE & PCR & IHC & Sample \\
\hline 27 & - & - & - & \multirow{10}{*}{ 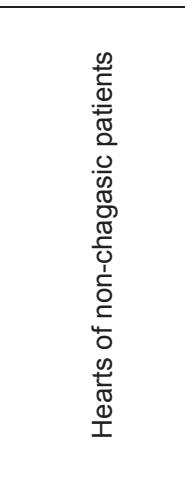 } \\
\hline 28 & - & - & - & \\
\hline 29 & - & - & - & \\
\hline 30 & - & - & - & \\
\hline 31 & - & - & - & \\
\hline 32 & - & - & - & \\
\hline 33 & - & - & - & \\
\hline 34 & - & - & - & \\
\hline 35 & - & - & - & \\
\hline 36 & - & - & - & \\
\hline 37 & - & - & - & \multirow{10}{*}{ 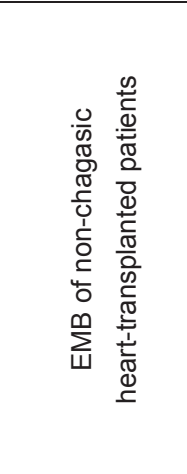 } \\
\hline 38 & - & - & - & \\
\hline 39 & - & - & - & \\
\hline 40 & - & - & - & \\
\hline 41 & - & - & - & \\
\hline 42 & - & - & - & \\
\hline 43 & - & - & - & \\
\hline 44 & - & - & - & \\
\hline 45 & - & - & - & \\
\hline 46 & - & - & - & \\
\hline 47 & - & - & - & \multirow{6}{*}{ 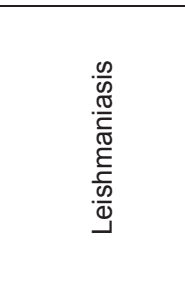 } \\
\hline 48 & - & - & - & \\
\hline 49 & - & - & - & \\
\hline 50 & - & - & + & \\
\hline 51 & - & - & - & \\
\hline 52 & - & - & - & \\
\hline 53 & - & ND & - & Toxoplasmosis \\
\hline 54 & - & ND & - & Histoplasmosis \\
\hline
\end{tabular}

\begin{tabular}{|c|c|c|c|c|}
\hline \multicolumn{5}{|c|}{ Cases } \\
\hline $\mathrm{N}^{\circ}$ case & HE & PCR & IHC & Sample \\
\hline 55 & - & + & + & \multirow{31}{*}{ 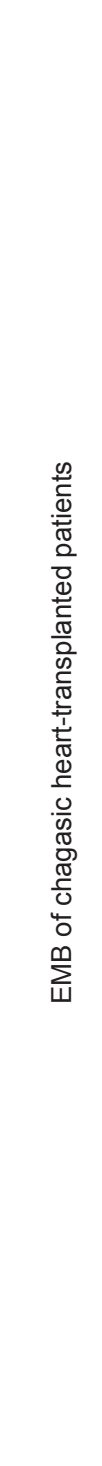 } \\
\hline 56 & - & + & + & \\
\hline 57 & - & + & + & \\
\hline 58 & - & + & + & \\
\hline 59 & - & + & - & \\
\hline 60 & - & + & - & \\
\hline 61 & - & + & - & \\
\hline 62 & - & + & - & \\
\hline 63 & - & + & - & \\
\hline 64 & - & + & - & \\
\hline 65 & - & + & - & \\
\hline 66 & - & + & - & \\
\hline 67 & - & + & - & \\
\hline 68 & - & + & - & \\
\hline 69 & - & + & - & \\
\hline 70 & - & + & - & \\
\hline 71 & - & + & - & \\
\hline 72 & - & + & - & \\
\hline 73 & - & + & - & \\
\hline 74 & - & + & - & \\
\hline 75 & - & + & - & \\
\hline 76 & - & + & - & \\
\hline 77 & - & + & - & \\
\hline 78 & - & + & - & \\
\hline 79 & - & + & - & \\
\hline 80 & - & + & - & \\
\hline 81 & - & + & - & \\
\hline 82 & - & + & - & \\
\hline 83 & - & + & - & \\
\hline 84 & - & + & - & \\
\hline 85 & - & + & - & \\
\hline
\end{tabular}

FIGURE 1: Results of Trypanosoma cruzi detection PCR, conventional histology using HE, and IHC of positive controls, negative controls, and cases. HE: hematoxylin and eosin; PCR: polymerase chain reaction; IHC: immunohistochemical reaction; EMB: endomyocardial biopsies; ND: not done. 


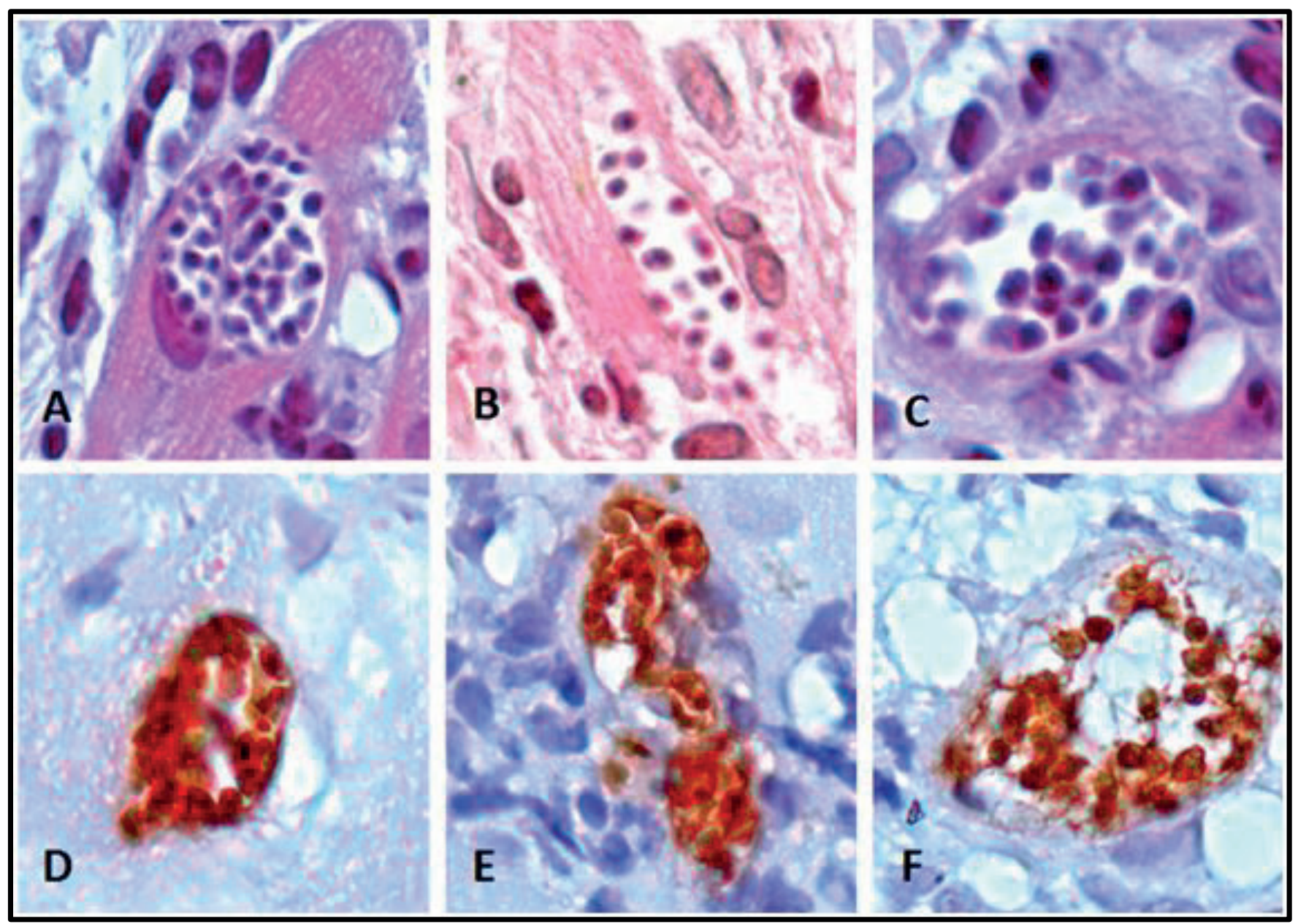

FIGURE 2: A, B, and C. Endomyocardial biopsies showing nests of amastigote forms of $T$. cruzi in the cytoplasm of myocardiocytes. Hematoxylin and eosin (1,000x magnification). D, E, and F. T. cruzi amastigote forms stained by the immunohistochemical reaction with anti-T. cruzi polyclonal antibody (1,000× magnification). T.: Trypanosoma.

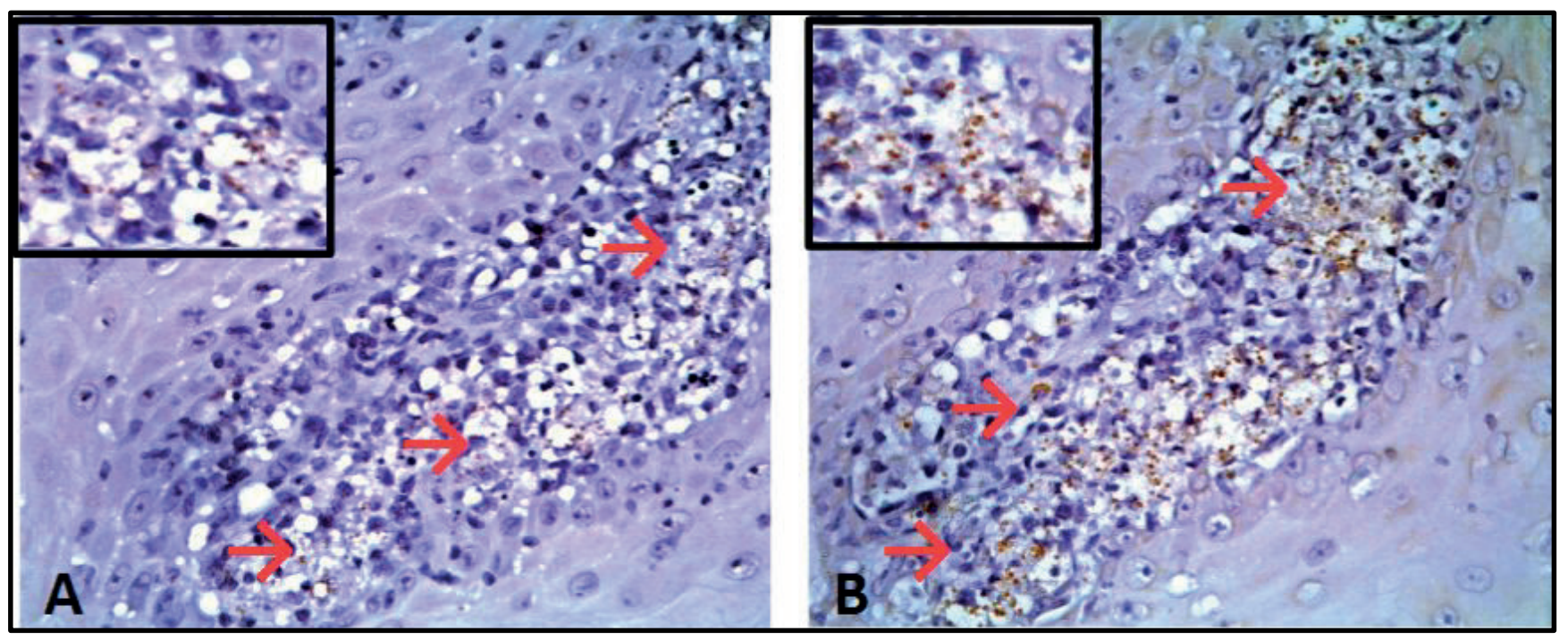

FIGURE 3: A. Skin biopsy of a patient with clinical and immunohistochemical diagnosis of cutaneous leishmaniasis showing parasitic amastigote forms dispersed in the interstitium, as stained with anti-T. cruzi antibody (arrows; $400 \times$ magnification). In detail, cross-reactive leishmania amastigote forms (1,000x magnification). B. Same biopsy and topography of the case shown in A revealing many amastigote forms of leishmania stained with antileishmania antibody. T.: Trypanosoma. 


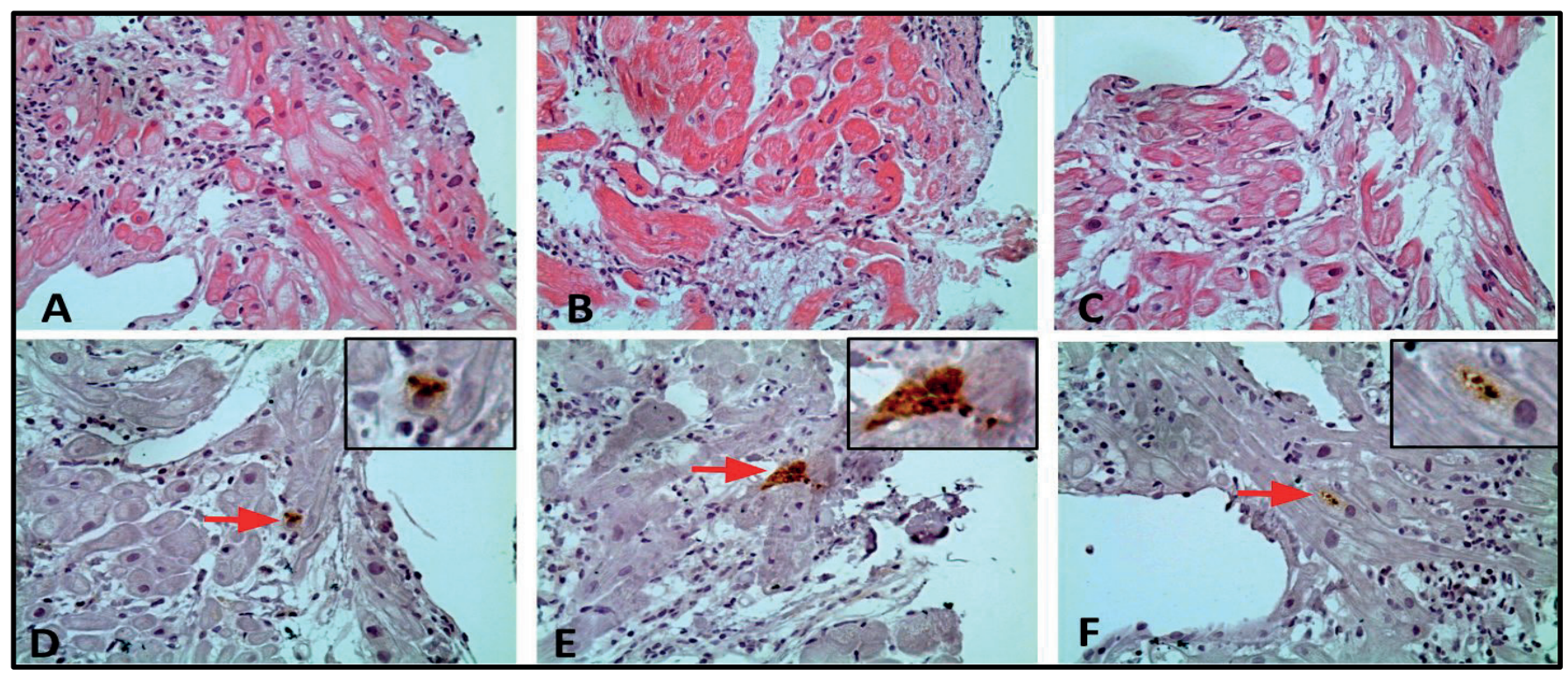

FIGURE 4: A, B, and C. Endomyocardial biopsies with no evidence of $T$. cruzi amastigote nests in histopathological examination using hematoxylin and eosin (200x magnification). D, E, and F. Same biopsies and topography of the cases shown in A, B, and C, respectively, with $T$. cruzi amastigote forms stained with anti-T. cruzi polyclonal antibody (arrows; 200× magnification). In detail, T. cruzi amastigote forms (1,000× magnification). T.: Trypanosoma.

samples showed negative results. None of the 26 negative controls were positive for T. cruzi DNA in the PCR test.

Four (12.9\%) of the 31 samples of EMB selected as cases were positive for T. cruzi nests with IHC (Figure 4); parasite nests were undetected by conventional histological examination.

From the 85 samples analyzed, $26(31.3 \%)$ had positive histopathology (T. cruzi amastigote nests), while the remaining $59(69.4 \%)$ cases showed negative HE staining (absence of T. cruzi nests).

Twenty-one of the $26(80.8 \%)$ samples selected as positive controls were positive for $T$. cruzi antigens in IHC test. Of the 28 negative controls, 27 (96.4\%) showed no reaction with T. cruzi antigens.

\section{DISCUSSION}

In comparison with the conventional HE staining, IHC performed with the antiserum used in this study showed good sensitivity for the detection of T. cruzi, indicative of the feasibility of this method for the detection of the parasite. Five EMB (19.2\% of positive controls) samples were negative for the parasite antigen in IHC. The most likely explanation for this result is the scarcity of the parasite nests and their small size, which may explain their absence in many histological sections. T. cruzi nests seen in the histological sections (HE) may not have been included in the sections obtained in the second microtomy; the paraffin block adjustment in the microtome to obtain new sections for IHC may have greatly deepened the sample, which explains the absence of these small and few nests in the sections used for IHC. Hence, it is recommended that the tissue sections are collected at the same time on slides for both conventional histopathology and IHC to include amastigote nests in most histological sections obtained. Such a technique is already performed in other contexts, wherein the target of analysis is scarce and may be lost in the acquisition of new sections, such as axillary sentinel node biopsies for the evaluation of patients with breast cancer ${ }^{36}$.

A cutaneous leishmaniasis sample was detected positive with the anti-T. cruzi antiserum in IHC. No other negative control sample showed positive reaction, indicative of the good specificity of the method. Anti-T. cruzi polyclonal antibody used in the present study may cross-react with other parasites and should therefore be used in close correlation with the clinical and laboratory data of the patient as well as obvious morphological correspondence to the histopathological examination in HE. Cross-reaction with antigens of leishmaniasis was also observed by Barbosa et al. ${ }^{37}$ using another antiserum against T. cruzi. Thus, it is recommended to use this method with large number of leishmaniasis cases to better understand the results and possible cross-reaction. Furthermore, it is necessary to test more specimens with anatomopathological diagnosis of other infectious diseases caused by parasites with morphologies similar to those of amastigote forms of T. cruzi (e.g., toxoplasmosis and histoplasmosis) to recognize other probable cross-reactions of the antibody under study.

The present study showed that IHC using anti-T. cruzi antiserum increases the chances of detection of the parasite in EMB. Four of 31 EBM harboring T. cruzi DNA, as detected by PCR, were positive for T. cruzi nests in IHC but were undetected by conventional histology. This increase in the sensitivity of the morphological diagnosis of the reactivation of chagasic infection supports the use of the method as a complementary evaluation technique in the EMB of transplanted chagasic patients.

The differential diagnosis between cell rejection and reactivation of chagasic infection has enormous importance in 
the case of transplant patients because the clinical management is very different in both situations. Thus, it is essential that, in addition to the conventional histopathological examination (HE) for the detection of parasite amastigote nests in all EMB of cardiac transplant patients with Chagas disease, the morphological evaluation should be complemented with IHC study. We suggest that the transplant patient care groups should include IHC as a routine test in the histopathological evaluation of all EMB in the care protocols to diagnose the reactivation of $T$. cruzi infection, at least for samples where mononuclear cell infiltration is evident. Given the small size of the nests and their occasional suppression in serial histological sections, IHC should be performed for at least three sequential cuts to increase the chances of the parasite detection.

The negativity of $T$. cruzi DNA in the PCR method for $15(57.7 \%)$ of the 26 positive controls may be attributed to some factors. The most likely reason is DNA degradation by formaldehyde used as fixative. Standard $10 \%$ formalin solution was used in all samples. Conventional (unbuffered) formaldehyde solutions have a wide $\mathrm{pH}$ range, which may cause DNA damage and impair DNA detection in $\mathrm{PCR}^{38}$. It is, therefore, recommended that such samples be fixed in buffered formaldehyde ( $\mathrm{pH}$ of 7.4) to increase the preservation of the parasite DNA and improve its detection chance.

As this study is at an initial stage, we were unable to adequately characterize the antibody studied. In fact, an antiserum with a large number and variety of antibodies was used in this study. The isolation and characterization of the antibody may provide further information on its properties and explain the possible cross-reactivity with leishmanial antigens.

The anti- $T$. cruzi polyclonal antibody (antiserum) used in this study proved to be adequate for the purpose of increasing the sensitivity of the morphological diagnosis of reactivation of chagasic infection. The increase in parasite detection observed in this study recommends the use of IHC with anti-T. cruzi antiserum tested herein as a complementary method in the early diagnosis of the reactivation of $T$. cruzi infection in chagasic patients submitted to heart transplantation.

It is also expected that commercial companies would get interested in providing antibodies for such purpose for the widespread clinical usage. We expect that the antiserum used herein could be an alternative to this.

\section{Conflict of interest}

The authors declare that there is no conflict of interest.

\section{REFERENCES}

1. Chagas C. Nova tripanozomiaze humana: estudos sobre a morfolojia e o ciclo evolutivo do Schizotrypanum cruzi n. gen., n. sp., ajente etiolojico de nova entidade morbida do homem. Mem Inst Oswaldo Cruz. 1990;1(2):159-218.

2. World Health Organization (WHO). Sustaining the drive to overcome the global impact of neglected tropical diseases: second WHO report in neglected tropical diseases. Geneva: WHO; 2013. 138p. Available at: http://www.who.int/iris/handle/10665/77950
3. World Health Organization (WHO). Chagas disease (American trypanosomiasis). Geneva: WHO; 2015. Available at: http://www. who.int/mediacentre/factsheets/fs340/en/

4. Coura JR, Dias JC. Epidemiology, control and surveillance of Chagas disease: 100 years after its discovery. Mem Inst Oswaldo Cruz. 2009;104(1):31-40.

5. Coura JR. The main sceneries of Chagas disease transmission. The vectors, blood and oral transmissions: a comprehensive review. Mem Inst Oswaldo Cruz. 2015;110(3):277-82.

6. Dias JCP. Human Chagas disease and migration in the context of globalization: some particular aspects. J Trop Med. 2013:p. 1-9. Article ID: 789758.

7. Manne-Goehler J, Umeh CA, Montgomery SP, Wirtz VJ. Estimating the burden of Chagas disease in the United States. PLoS Negl Trop Dis. 2016;7;10(11):e0005033.

8. Luna EJ, Furucho CR, Silva RA, Wanderley DM, Carvalho NB, Satolo CG, et al. Prevalence of Trypanosoma cruzi infection among Bolivian immigrants in the city of São Paulo, Brazil. Mem Inst Oswaldo Cruz. 2017;112(1):70-74.

9. Rassi Jr A, Rassi A, Marin-Neto JA. Chagas disease. Lancet. 2010;375(9723):1388-402.

10. Dolgin M, Association NYH, Fox AC, Gorlin R, Levin RI. The Criteria Committee of the New York Heart Association.. Nomenclature and criteria for diagnosis of diseases of the heart and great vessels. $9^{\text {th }}$ edition. Boston, MA: Lippincott Williams and Wilkins; 1994. p.253-6.

11. Fiorelli AI, Santos RH, Oliveira JL Jr, Lourenço-Filho DD, Dias RR, Oliveira AS, et al. Heart transplantation in 107 cases of Chagas' disease. Transplant Proc. 2011;43(1):220-4.

12. Godoy HL, Guerra CM, Viegas RF, Dinis RZ, Branco JN, Neto VA, et al. Infections in heart transplant recipients in Brazil: the challenge of Chagas' disease. J Heart Lung Transplant. 2010;29(3):286-90.

13. Ferreira MS, Nishioka AS, Rocha A. Doença de Chagas e imunossupressão. In: Dias JCP, Coura JR, editors. Clínica e Terapêutica da Doença de Chagas- Uma Abordagem Prática para o Clínico Geral. Rio de Janeiro: FIOCRUZ; 1997. p. 365-81.

14. Campos SV, Strabelli TM, Amato Neto V, Silva CP, Bacal F, Bocchi EA, et al. Risk factors for Chagas' Disease reactivation after heart transplantation. J Heart Lung Transplant. 2008;27(6):597-602.

15. Bocchi E, Bellotti D, Uip J, et al. Long-term follow-up after heart transplantation in Chagas' disease. Transplant Proc. 1993;25(1pt2):1329-30.

16. Stolf NA, Higushi L, Bocchi E, Bellotti G, Auler JO, Uip D, et al. Heart transplantation in patients with Chagas' disease cardiomyopathy. J Heart Transplant. 1987;6(5):307-12 .

17. d'Avila SC, d'Avila AM, Pagliari C, Gonçalves VM, Duarte MI. Eritema nodoso como forma de reativação da doença de Chagas em transplantado cardíaco. Rev Soc Bras Med Trop. 2005,38(1):61-3.

18. Dias JC, Ramos AN Jr, Gontijo ED, Luquetti A, Shikanai-Yasuda MA, Coura JR, et al. $2{ }^{\text {nd }}$ Brazilian Consensus on Chagas Disease, 2015. Rev Soc Bras Med Trop. 2016;49(Suppl1):3-60.

19. Virreira M, Torrico F, Truyens C, Alonso-Vega C, Solano M, Carlier Y, et al. Comparison of polymerase chain reaction methods for reliable and easy detection of congenital Trypanosoma cruzi infection. Am J Trop Med Hyg. 2003;68(5):574-82.

20. Benvenuti LA, Rogério A, Sambiase NV, Fiorelli A, Higuchi ML. Polymerase chain reaction in endomyocardial biopsies for monitoring reactivation of Chagas' disease in heart transplantation: a case report and review of the literature. Cardiovasc Pathol. 2005;14(5):265-8. 
21. Maldonado C, Albano S, Vettorazi L, Salomone O, Zlocowski $\mathrm{JC}$, Abiega C, et al. Using polymerase chain reaction in early diagnosis of re-activated Trypanosoma cruzi infection after heart transplantation. J Heart Lung Transplant. 2004;23(12):1345-8.

22. Wincker P, Britto C, Pereira JB, Cardoso MA, Oelemann W, Morel $\mathrm{CM}$. Use of a simplified polymerase chain reaction procedure to detect Trypanosoma cruzi in blood samples from chronic chagasic patients in a rural endemic area. Am J Trop Med Hyg. 1994;51(6):771-7.

23. Nair V, Butany J. Heart transplant biopsies: interpretation and significance. J Clin Pathol. 2010;63(1):12-20.

24. Pinazo MJ, Miranda B, Rodríguez-Villar C, Altclas J, Brunet Serra M, García-Otero EC, et al. Recommendations for management of Chagas disease in organ and hematopoietic tissue transplantation programs in nonendemic areas. Transplant Rev (Orlando). 2011;25(3):91-101.

25. Souza MM, Franco M, Almeida DR, Diniz RV, Mortara RA, Silva $\mathrm{S}$, et al. Comparative histopathology of endomyocardial biopsies in Chagasic and non-Chagasic heart transplant recipients. J Heart Lung Transplant. 2001;20(5):534-43.

26. Barbosa AJ. Immunocytochemical method for the identification of Trypanosoma cruzi amastigotes in routine histological sections. Rev Inst Med Trop Sao Paulo. 1985;27(6):293-7.

27. Barbosa AJ, Gobbi H, Lino BT, Lages-Silva E, Ramirez LE, Teixeira VP, et al. Comparative study of the conventional method and the peroxidase-antiperoxidase method in the search for tissue parasitism in chronic Chagas' cardiopathy. Rev Inst Med Trop Sao Paulo. 1986;28(2):91-6.

28. Fuenmayor C, Higuchi ML, Carrasco H, Parada H, Gutierrez $\mathrm{P}$, Aiello V, et al. Acute Chagas' disease: immunohistochemical characteristics of T cell infiltrate and its relationship with T. cruzi parasitic antigens. Acta Cardiol. 2005;60(1):33-7.

29. Pittella JE, Meneguette C, Barbosa AJ, Bambirra EA. Histopathological and immunohistochemical study of the brain in the acute and chronic phases of experimental trypanosomiasis cruzi in dogs. Ann Trop Med Parasitol. 1990;84(6):615-21.

30. Caliari MV, de Lana M, Cajá RA, Carneiro CM, Bahia MT, Santos $\mathrm{CA}$, et al. Immunohistochemical studies in acute and chronic canine chagasic cardiomyopathy. Virchows Arch. 2002;441(1):69-76.

31. Pittella JE, Meneguette C, Barbosa AJ. Histopathological and immunohistochemical study of the brain and heart in the chronic cardiac form of Chagas' disease. Arq Neuropsiquiatr. 1993;51(1):8-15.

32. Higuchi ML, De Brito T, Martins Reis M, Barbosa A, Bellotti G, Pereira-Barreto AC, et al. Correlation between Trypanosoma cruzi parasitism and myocardial inflammatory infiltrate in human chronic chagasic myocarditis: Light microscopy and immunohistochemical findings. Cardiovasc Pathol. 1993;2(2):101-6.

33. Bacal F, Souza Neto JD, Fiorelli AI, Mejia J, Marcondes-Braga FG, Mangini S, et al. II Diretriz Brasileira de Transplante Cardíaco. Arq Bras Cardiol. 2009;94(1supl):e16-e-76.

34. Freitas JM, Lages-Silva E, Crema E, Pena SD, Macedo AM. Real time PCR strategy for the identification of major lineages of Trypanosoma cruzi directly in chronically infected human tissues. Int J Parasitol. 2005;35(4):411-7.

35. Costa PA, Segatto M, Durso DF, de Carvalho MWJ, Junqueira LL, de Castilho FM, et al. Early polymerase chain reaction detection of Chagas' disease reactivation in heart transplant patients. J Heart Lung Transplant. 2017;36(7):797-805.

36. Silverberg SG. Sentinel node processing: recommendations for pathologists. Am J Surg Pathol. 2002;26(3):383-5.

37. Barbosa AJ, da Costa CA, Michalick MS, Mayrink W, Gazzinelli RT, Tafuri WL. Immunocytochemical identification of Leishmania and Trypanosoma cruzi amastigotes in situ with homologous and heterologous polyclonal antibodies. Rev Soc Bras Med Trop. 1991;24(1):5-11.

38. Fernandes JV, Meissner RV, Fernandes TAAM, da Rocha LRM, Cabral MC, Villa LL. Comparison of three DNA extraction protocols from formaldehyde and paraffin-embedded tissues. J Bras de Patol Med Lab. 2004;40(3):141-6. 